\title{
Obesity-Related Renal Injury in Childhood
}

\author{
Alessandra Savino Piernicola Pelliccia Francesco Chiarelli Angelika Mohn \\ Department of Pediatrics, University of Chieti, Chieti, Italy
}

\section{Key Words}

Obesity, children $\cdot$ Renal injury $\cdot$ Insulin sensitivity

\begin{abstract}
A significant increase in the prevalence of end-stage renal disease (ESRD) has been reported over the last three decades, paralleling the increasing prevalence of obesity and insulin resistance, also in the pediatric population. Overweight, obesity and the metabolic syndrome, which frequently coexist, contribute substantially to cardiovascular disease and ESRD. A higher body mass index, the presence of type 2 diabetes, hypertension and, of particular importance, reduced insulin sensitivity (IS), have recently emerged as strong independent risk factors for chronic kidney disease and ESRD. Of particular concern, the long-term cardiovascular impact of obesity, although deferred to adult life, has its origins in childhood. Clustering of cardiovascular risk factors is seen in children and adolescents with the highest degree of reduced IS, suggesting that adult consequences of obesity on target organs, including the kidney, are more likely to develop in these young people. This review will discuss the association between obesity and the risk of kidney disease, focusing on the way in which obesity and its metabolic complications may lead to renal involvement and injury, with particular regard to childhood. It is beyond the scope of this article to examine kidney disease as a component of syndromes that result in obesity in childhood.
\end{abstract}

Copyright $\odot 2010$ S. Karger AG, Basel

\section{Introduction}

Childhood obesity is fast becoming a worldwide epidemic, with a continuous increase in prevalence that has tripled in the last three decades [1]. At present, approximately one fifth of children and adolescents in industrialized countries are overweight or obese, and the average prevalence has reached approximately $10 \%$ in a large number of developing countries [2]. Projections based on the IOTF indicate that by 2020 the prevalence of childhood overweight and obesity will be $>35 \%$ in Europe and $>45 \%$ in America; even in Southeast Asia, the average prevalence will reach $20 \%$ [2].

All these data are alarming and underline how obesity is a real threat not only for adults, but also for the health of children and adolescents [3], since metabolic as well as cardiovascular complications of obesity may already be evident at a young age [4].

A dramatic rise in the prevalence of end-stage renal disease (ESRD), which has more than doubled in the past decade [5], is also paralleling the obesity epidemic [2]. The increasing incidence and cost of ESRD are worldwide public-health problems, and identification of modifiable risk factors for ESRD is critical to the development of effective, population-based preventive strategies [2].

Several epidemiologic studies have clearly demonstrated that obesity increases the risk of kidney disease [2], as well as its progression among diagnosed kidney disease patients $[2,6]$. Obesity is strongly associated with

\footnotetext{
Alessandra Savino, MD

University Department of Pediatrics, Ospedale Policlinico

Via dei Vestini 5

IT-66013 Chieti (Italy)

Tel. +39 087135 8015, Fax +39 087157 4831, E-Mail alessavino@katamail.com
} 
the two most common causes of ESRD, namely diabetes and hypertension; moreover, the metabolic syndrome, a major consequence of obesity, also seems to be an independent risk factor for both chronic kidney disease (CKD) and ESRD [7], with accumulating data supporting the hypothesis that a reduced insulin sensitivity and hyperinsulinemia are among the most important factors of metabolic syndrome contributing to renal injury [8].

The vast majority of studies that examined the association between obesity and kidney disease have been conducted in adults [2]. The efforts in children have so far been very limited. However, growing evidence suggests that childhood obesity also increases the risk of kidney disease and its consequences [2], and that renal dysfunction may start long before the appearance of hypertension or diabetes in adulthood [7]. The long-term cardiovascular and renal impact of obesity, although deferred to adult life, has its origin in childhood [9].

\section{Pathophysiology of Obesity-Related Renal Injury}

Clinically characterized by a higher serum albumin, a lower incidence of nephrotic-range proteinuria, moderate proteinuria, lower serum cholesterol, and minimal edema [9], the so termed 'obesity-related glomerulopathy' [10] is defined morphologically as glomerulomegaly with or without focal segmental glomerulosclerosis (FSGS), due to functional and structural renal changes.

The first association between massive obesity and nephrotic-range proteinuria was reported in 1974 [11]. One year later, Cohen [12] described the presence of significant glomerular enlargement, mild hypercellularity, and variable widening of mesangial regions in severely obese patients with normal renal function; of particular concern, these features had been observed even in children as young as 3 years of age. Since that time, the development of glomerulomegaly and FSGS has been repeatedly linked to massive obesity.

There is strong evidence that obesity, in particular central body fat distribution, is important for renal function abnormalities [13]. In fact, overweight and obesity are strongly associated with numerous cardiovascular disease risk factors, i.e. hyperinsulinemia, impaired glucose metabolism, hypertension, hyperlipidemia and metabolic syndrome, which, apart from predisposing to cardiovascular disease, are also independent risk factors for CKD [8]. Above all, reduced insulin sensitivity represents the most important link between obesity and other metabolic complications leading to renal injury [14] (fig. 1).
Obesity is associated with glomerular hyperperfusion and hyperfiltration from physiologic maladaptation that results from afferent arteriolar vasodilatation. Hyperinsulinemia, a marker of a reduced insulin sensitivity, seems to play a pivotal role in the pathogenesis of renal hemodynamic abnormalities. At the tubular level, insulin has an antinatriuretic effect, increasing sodium reabsorption, without affecting glomerular filtration rate (GFR), renal plasma flow, filtered load of glucose, and plasma aldosterone levels [15]. At the glomerular level, insulin is related to contradicting effects on GFR. In experimental studies, it seems to slightly increase GFR, possibly due to its direct vasodilatory effect [16] or to its antinatriuretic effect. On the other hand, in healthy humans, hyperinsulinemia under euglycemic conditions was previously reported not to affect GFR and renal plasma flow either $[15,17]$. However, a more recent study by Chagnac et al. [18] demonstrated a strong relation between GFR and a reduced insulin sensitivity; they also suggested that the high GFR in very obese subjects may be the result of an increase in transcapillary hydraulic pressure difference. Hyperinsulinemia also seems to be related to a direct and selective increase in urinary albumin excretion rate (U-AER) in type 2 diabetes mellitus (T2DM) patients, without affecting systemic albumin permeability. Microalbuminuria and variable degrees of proteinuria are also positively correlated with the severity of obesity $[10,19,20]$, such as with body mass index (BMI) [21] and changes in weight [22]; measures that enhance insulin sensitivity, reduce blood pressure, and improve glycemic control have all been shown to reduce microalbuminuria [23]. Moreover, insulin interferes at several points in the systemic renin-angiotensin-aldosterone system, increasing its activity despite a state of sodium retention and volume expansion [23]. Insulin also increases the effects of angiotensin II on mesangial cells [24], thus contributing to hypertension, raised intraglomerular pressure, exacerbation of proteinuria, induction of intrarenal inflammatory cytokines and growth factors, and apoptosis [25]. Insulin per se can promote the proliferation of mesangial cells and the production of extracellular matrix proteins, altering the type of interstitial and basement membrane collagens excreted by mesangial cells [26]. It also stimulates the expression of other growth factors, such as IGF-1 [27] and TGF- $\beta 1$ [28], which are involved in numerous mitogenic and fibrotic processes of diabetic nephropathy $[28,29]$, and in increasing the activity of the connective tissue growth factor, which has profibrogenic actions on renal tubular cells and interstitial fibroblasts [30]. Visceral-type adiposity is 


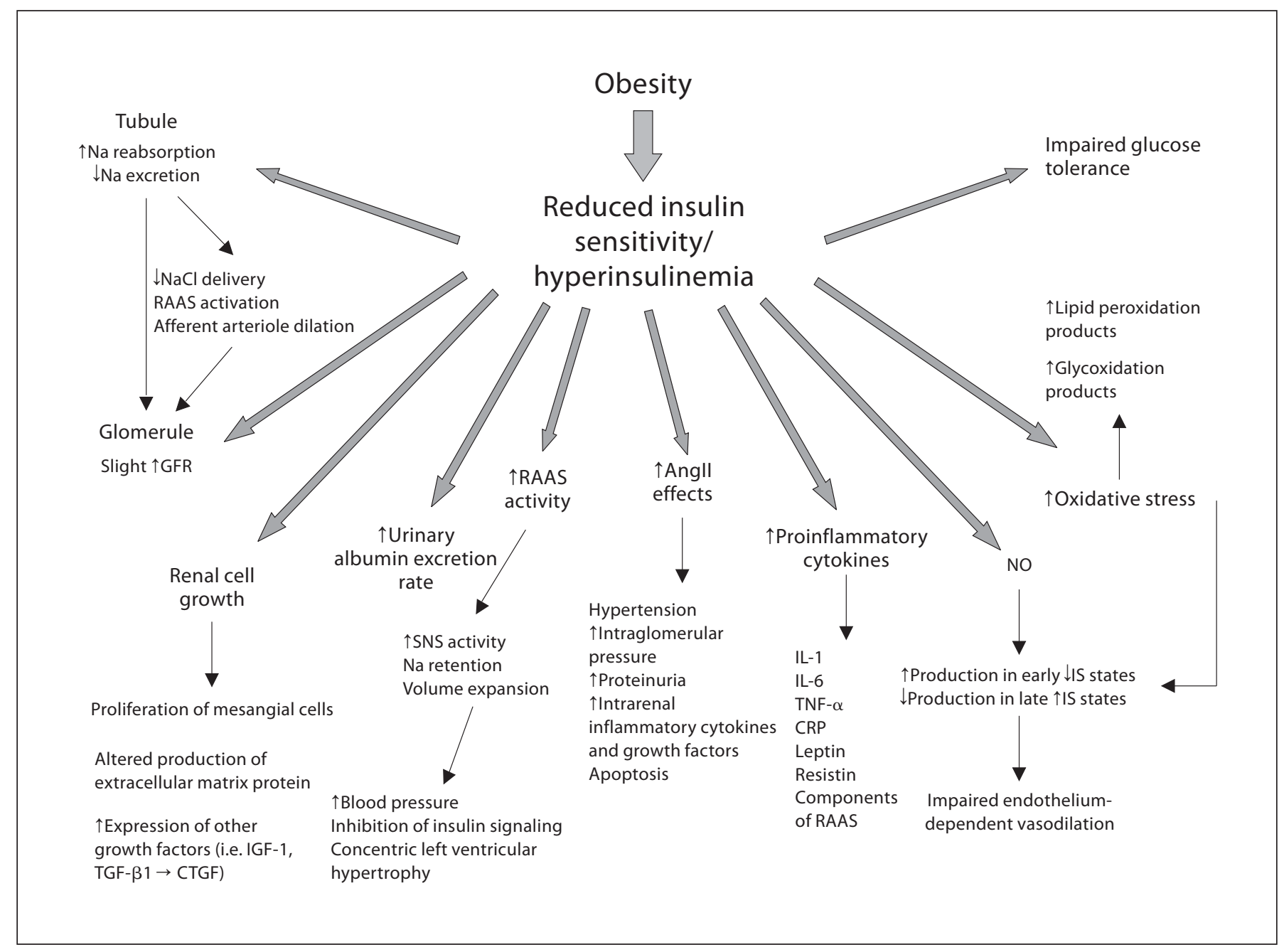

Fig. 1. Through different pathways reduced insulin sensitivity and hyperinsulinemia may lead to renal involvement and injury. $\mathrm{Na}=$ Sodium; $\mathrm{NaCl}$ = sodium chloride; RAAS = renin-angiotensin-aldosterone system; GFR = glomerular filtration rate; IGF-1 = insulin-like growth factor-1; TGF- $\beta=$ transforming growth factor- $\beta$; CTGF = connective tissue growth factor; SNS = sympathetic nervous system; AngII = angiotensin II; IL-1 = interleukin-1; IL-6 = interleukin-6; TNF- $\alpha=$ tumor necrosis factor- $\alpha$; CRP $=$ C-reactive protein; $\mathrm{NO}=$ nitric oxide; IS = insulin sensitivity.

characterized by dysfunctional adipose tissue, that is a known source of proinflammatory cytokines, including components of the renin-angiotensin-aldosterone system, tumor necrosis factor- $\alpha$, interleukin-1, interleukin-6, C-reactive protein, leptin, and resistin, all implicated in reducing insulin sensitivity [31,32]; many of them have also been suggested to mediate kidney disease pathophysiology, contributing to glomerular mesangial expansion, podocyte remodeling, loss of slit pore diaphragm integrity, and basement membrane thickening [32]. Finally, the degree of insulin sensitivity is closely as- sociated with markers of oxidative stress and inversely with the levels of antioxidant substances [33], which in turn promote renal injury through various pathways and contribute to the progression of kidney damage. Increased markers of oxidative stress have been reported both in patients with early diabetic nephropathy and in patients with stage III-IV CKD due to various causes [34]. Several mechanisms have been postulated; one of them is the involvement of oxidative stress in the decreased nitric oxide (NO) production and availability, which plays a role in advanced stages of nephropathy. The 
degree of insulin sensitivity is related to the endothelial NO production [35], and studies conducted in the obese population $[36,37]$ showed reduced $\mathrm{NO}$ levels vs. normal weight controls, thus suggesting a role of reduced insulin sensitivity to endothelial dysfunction. Moreover, in obese individuals with reduced insulin sensitivity, the conjunction of sympathetic over-activity and impaired NO synthesis seems to favor hypertension and potentiate overall cardiovascular risk [38].

\section{Obesity-Related Renal Injury in Childhood}

Concomitant with the global obesity epidemic, the prevalence of overweight and obesity among children and adolescents has dramatically increased [2]. Sequelae of obesity, such as hypertension, dyslipidemia and hyperinsulinemia, are increasingly recognized in children, together with obstructive sleep apnea, hepatic fatty infiltration, and orthopedic complication. Obesity-related glomerulopathy, a secondary form of FSGS, presenting as proteinuria and progressive renal dysfunction that results from a maladaptative glomerular response to increasing adiposity, also showed an increasing incidence during the last 20 years, even in the pediatric population.

\section{Childhood Obesity and Risk of Renal Injury}

Few studies have examined the association between childhood obesity and kidney disease in the general population. Nevertheless, growing evidence, predominantly based on studies conducted among patients, suggests that childhood obesity may put young people at increased risk of kidney disease and the consequences (e.g. development of kidney disease, allograft function loss, kidney function deterioration to ESRD, and patient death) [2].

Childhood obesity increases the risk of mortality caused by kidney disease. A 7-year follow-up study testing the association between anthropometric measurements and death among 3,067 pediatric patients with ESRD found a statistically significant association between baseline BMI and pediatric ESRD death [39]. Obesity is also an increasing problem in children who present for transplantation, and may have an adverse effect on allograft and patient survival. Pretransplantation obesity and increased BMI after renal transplant are found to be associated with decreased long-term renal allograft survival in adult and pediatric patients [40,41]. Excess of body weight also seems to be a prognostic factor in the development of hypertension and progression to CKD in IgA nephropathy [42].
Of particular concern, Filler et al. [43] recently reported a significant increase in BMI $\mathrm{z}$-score in their pediatric nephrology population over the last three decades, with an overall BMI z-score higher than the comparable USA young population in the same period. This puts young nephrology patients at even greater risk of developing CKD later in life than could be depicted from their renal disease only.

The physiological (mal)adaptation in renal hemodynamics in obesity is comprised of hyperfiltration associated with hyperperfusion, which together play a role in renal injury. An increased GFR was observed in overweight compared with lean subjects, being significantly positively related to BMI [44] and insulin resistance [18].

Rare reports of obesity-related glomerulopathy have documented ESRD in children and adolescents, but more frequently obese young patients presented with enhanced U-AER [45], microalbuminuria [45, 46], progressing to the nephrotic range proteinuria caused by FSGS $[19,47]$.

Another important finding is the observation that obese children present larger kidneys than those of normal weight patients, as a consequence of the increased weight, which strongly correlated with the size of various organs [48].

It is noteworthy that obesity may not only be associated with kidney disease because it induces renal damage or enhances renal failure progression in patients with established kidney disease [49], but obesity and kidney disease may also coexist because they may be features of the same condition. The causes of obesity are many, with endocrine and genetic factors playing an important role; the vast majority of syndromes associated with obesity are often characterized by many other manifestations, including renal abnormalities, with reciprocal impairment in a vicious circle. Bardet-Biedl syndrome and Alport syndrome are two obvious examples [50]. This is an important aspect that deserves a special mention, especially in children, since many of these conditions start in childhood or exhibit symptoms within the first years of age. Moreover, prenatal risk factors for obesity, such as being born small for gestational age or born preterm and appropriate for gestational age, in addition to imposing an additional risk of hypertension, reduced insulin sensitivity and T2DM later in life, are also risk factors for reduced nephron mass and progression of kidney disease in childhood, with an increased risk for ESRD [51].

Nonetheless a review of kidney disease associated with the cause of obesity in children is beyond the scope of this article. 


\section{Childhood Obesity, Reduced Insulin Sensitivity and Renal Injury}

As mentioned above, one of the most important consequences of obesity is the development of a state of reduced insulin sensitivity. Obese children with a similar BMI can differ on the basis of the degree of insulin sensitivity in the risk of complications [3]. Clustering of cardiovascular risk factors, such as hypertension, proteinuria, T2DM and dyslipidemia, is seen in children and adolescents with a lower degree of insulin sensitivity, suggesting that the adult consequences of obesity on target organs, including the kidney, are more likely to develop in these young people [4].

Hyperinsulinemia, a marker of insulin sensitivity, is strongly associated with obesity during adolescence because of a physiological decrease in insulin sensitivity associated with normal pubertal development, but more alarming is that metabolic and cardiovascular complications are already found in obese prepubertal children, as reduced insulin sensitivity and related consequences might be further exacerbated by the influence of puberty [52].

Hyperinsulinemia influences blood pressure and serum lipoprotein concentrations, and often results in hypertension and dyslipidemia. The presence of these conditions, in addition to obesity, is thought to play a key role in the pathogenesis of obesity-related glomerulopathy.

\section{Childhood Obesity, Hypertension and Renal Injury}

The association between hypertension and childhood overweight and obesity has been documented in several studies [9]. In general, blood pressure values have increased among youths over the last decade, in parallel with the rise in obesity [53]; this results in more children and adolescents falling into hypertensive ranges. Sorof et al. [54] found the prevalence of hypertension increases progressively in school children as the BMI percentile increased from $<5$ th to $>95$ th percentile with a relative risk of 3.26 in obese children. The risk of hypertension increases across the entire range of BMI values and is not defined by a simple threshold effect $[55,56]$. In a large meta-analysis, Rosner et al. [57] found that, compared with normal weight children, those with a BMI of $>90$ th percentile were 2.5-3.7 times more likely to have hypertension. Nawrot et al. [58] reported that systolic blood pressure increases by $0.8 \mathrm{~mm} \mathrm{Hg}$ per $1-\mathrm{kg} / \mathrm{m}^{2}$ increase in $\mathrm{BMI}$ in 15- to 19-year-old males and by $1.2 \mathrm{~mm} \mathrm{Hg}$ in females. In the Framingham Offspring Study, the risk of hypertension can be directly attributed to excess body weight in $78 \%$ of young men and $65 \%$ of young women
[59]. Lurbe et al. [60] found both casual blood pressure and ambulatory blood pressure to be significantly higher among obese children, with ambulatory blood pressure monitoring having significantly higher blood pressure values over $24 \mathrm{~h}$, and the magnitude of the difference being similar during both daytime and nighttime periods. The prevalence of pre-hypertension is also increasing through childhood, especially among adolescents, as a consequence of weight gain [61]. In a high risk population for ESRD, Aboriginal Australians, Haysom et al. [62] showed that only $20 \%$ of prepubertal children found to have markers of early CKD had persistent abnormalities (diastolic and systolic hypertension, albuminuria and hematuria) 2 years later, while persistent obesity was frequent, suggesting that adolescence and young adulthood is a more critical time for preventive strategies. In a rural community in Canada, Salvadori et al. [63] found a strong relationship between overweight and obesity with both hypertension and pre-hypertension. Blood pressure levels that are in the pre-hypertension range, as well as in the hypertension range, are considered high-risk blood pressure levels [61]. Low insulin sensitivity is a well-known contributor of high blood pressure in children [3, 64]. Whereas in some studies this has been attributed to the effect of obesity itself, in others reduced insulin sensitivity has emerged as a predictor of blood pressure, independent of BMI $[65,66]$. Data from a longitudinal study in Pima Indians showed that childhood systolic blood pressure and BMI, both measures related to adiposity, independently predict adult insulin action; this implies that excess adiposity during development may have adverse effects independent of later body size [67]. The association of childhood systolic blood pressure with adult insulin action may reflect common underlying mechanisms that begin early in life and may be as simple as a sedentary lifestyle, or more complex such as sympathetic hyperfunction or increased inflammation. An insulin-mediated effect on renal sodium reabsorption and the sympathetic nervous system is the main mechanism suggested as a potential link between reduced insulin sensitivity and increased blood pressure [3]. A state of hyperactivity of the sympathetic nervous system, including increased heart rate, blood pressure variability, increased levels of catecholamine and increased peripheral sympathetic nerve traffic, has also been described in obese children [56].

The kidney is both a cause and victim of hypertension [68]. In the presence of lower insulin sensitivity, dysglycemia and dyslipidemia, both precursors of higher blood pressure, may contribute to renal injury, leading to grad- 
ual nephron loss. Functional and structural nephron loss may also contribute to elevated blood pressure [23]. Reduced GFR has already been found in pre-hypertensive children with high blood pressure load, as well as increased proteinuria, suggesting that even mild elevated blood pressure puts patients at risk of developing renal damage [69].

\section{Childhood Obesity, Microalbuminuria and Renal Injury}

Microalbuminuria is quite common in obese children and adolescents. In obese and pre-diabetic youths, Burgert et al. [46] found microalbuminuria to have a prevalence of $10 \%$, consistent with previous findings in obese adults, and to have a strong positive relation to post-challenge alterations in glucose metabolism and overall loss of insulin sensitivity. Not obesity per se, but the metabolic consequences of obesity seem to be the driving forces behind U-AER, and even slight abnormalities in glucose metabolism below the diagnostic cutoff for diabetes contributed to the presence of microalbuminuria. Similarly, Verhulst et al. [70] found that insulin resistance and, over all, post-challenge glucose levels were the most important predictors of U-AER in obese children with sleep-disordered breathing. In a pediatric population-based study, Csernus et al. [45] observed increased levels of albuminuria and $\beta_{2}$-microglobulinuria in obese versus normal weight children, indicating early renal glomerular and tubular dysfunction as a consequence of childhood obesity. The urinary albumin/creatinine ratio was related to the presence of some features of the metabolic syndrome, but not with others; in particular, significant associations were found with hyperinsulinemia and impaired glucose tolerance. In an interesting longitudinal study on a multiethnic sample of young adults followed for 6 years, Ferris et al. [71] observed that microalbuminuria was strongly related only to the severe obesity, since the highest level of BMI ( $\geq 35$ ), but not the lower, was associated with albuminuria. Moreover, a change in BMI over 6 years, but not baseline BMI, was associated with albuminuria at follow-up, suggesting that growth in body mass may occur faster than the kidneys can adapt.

The relationship between microalbuminuria and excess weight is more complicated in adolescents, and previous studies came to seemingly discrepant conclusions [72].

Overweight adolescents, with presumably more coexisting cardiovascular risk factors, had a lower prevalence of microalbuminuria $[73,74]$, approximately $8.9 \%$, with a higher prevalence among non-overweight than overweight, thus suggesting the existence of important confounding variables, e.g. orthostatic proteinuria. Nonetheless, the association of microalbuminuria with cardiovascular risk factors differed according to the BMI category, which was strongly modified by overweight [75].

\section{Childhood Obesity, Impaired Glucose Metabolism and Renal Injury}

T1DM commonly occurs in childhood, although many pediatric centers are now seeing more cases of T2DM [76]. Being overweight/obese is the most important risk factor for the development of T2DM, even in youths. The increasing prevalence of overweight closely parallels the rise in T2DM among children and adolescents [77, 78]. In 1994, T2DM accounted for one third of the newly diagnosed diabetes cases among 10- to 19-yearolds [79], $90 \%$ of those having BMI values of $\geq 90$ th percentile for age and gender. Impaired glucose tolerance and reduced insulin sensitivity are intermediate stages in the development of T2DM [80].

Kidney failure caused by either type of diabetes is uncommon during childhood, but these years of hyperglycemia contribute to long-term complications. Screening of GFR, blood pressure and U-AER should start at the time of diagnosis of T2DM in young patients, and atypical features, such as dipstick-positive proteinuria or active urine sediment, may warrant referral to a nephrologist for evaluation [74]. Diagnosis of renal disease in children with T2DM cannot be reliably determined by clinical and laboratory findings alone: renal biopsy is necessary for accurate diagnosis, with non-diabetic nephropathy in the form of immune complex disease or glomerulosclerosis being the most common etiology of macroalbuminuria in this young population [81].

\section{Childhood Obesity, Dyslipidemia and Renal Injury}

Obese children and adolescents have consistently been observed to have more unfavorable lipid and lipoprotein profiles than children and adolescents with normal body weights [4], and this places them at greater cardiovascular risk than their non-obese peers, particularly during puberty [82]. Glowinska et al. [83] have shown that obese adolescents have significantly higher LDL cholesterol and triglyceride concentrations and significantly lower HDL cholesterol concentrations than age-matched lean controls. Friedland et al. [75] observed that $52 \%$ of obese children aged 8-12 years old have elevated total cholesterol concentrations compared with a prevalence of $16 \%$ in 
non-obese children. At-risk lipoprotein concentrations during the growing years are of particular concern because they tend to track into adulthood [84]. As demonstrated in the Bogalusa Heart Study, the best predictor of young adult total cholesterol concentrations was measurement taken 12 years previously, and approximately $50 \%$ of children and adolescents who had total cholesterol or LDL cholesterol concentrations above the 75th percentile had elevated concentrations at follow-up in young adulthood [85]. Dyslipidemia contributes to the rate of progression of atherosclerosis and renal disease.

\section{Conclusions}

There is clear evidence that, in adults, excess body weight is significantly associated with an increased risk of kidney disease. A similar association has also been documented in obese children and adolescents, even though there is a lack of large and long-term studies.

A higher BMI, the presence of T2DM, hypertension and, of particular importance, reduced insulin sensitivity are strong independent risk factors for CKD and ESRD, which may be present even among overweight and obese children and adolescents. This is alarming, since in most cases the state of being overweight/obese tracks into adulthood, thus representing a major contributor to the adult obesity epidemic and to the increased cardiovascular and renal morbidity and mortality in adult life.

Obesity is a strong and potentially modifiable risk factor for the development and progression of kidney disease. Efforts to prevent and treat obesity early in life can be expected to have a major impact on the incidence, progression, costs and comorbidities of kidney disease.

\section{References}

$\checkmark 1$ Ogden CL, Carroll MD, Curtin LR, McDowell MA, Tabak CJ, Flegal KM: Prevalence of overweight and obesity in the United States, 1999-2004. JAMA 2006;295:1549-1555.

>2 Wang Y, Chen X, Klag MJ, Caballero B: Epidemic of childhood obesity: implications for kidney disease. Adv Chronic Kidney Dis 2006;13:336-351.

-3 Chiarelli F, Marcovecchio ML: Insulin resistance and obesity in childhood. Eur J Endocrinol 2008;159:S67-S74.

4 Jolliffe CJ, Janssen I: Vascular risks and management of obesity in children and adolescents. Vasc Health Risk Manag 2006;2:171187.

5 USRDS: The United States Renal Data System. Am J Kidney Dis 2003;42:1-230.

-6 Wang Y, Chen X, Song Y, Caballero B, Cheskin LJ: Association between obesity and kidney disease: a systematic review and meta-analysis. Kidney Int 2008;73:19-33.

7 Wahba IM, Mak RH: Obesity and obesityinitiated metabolic syndrome: mechanistic links to chronic kidney disease. Clin J Am Soc Nephrol 2007;2:550-562.

$\checkmark 8$ Sarafidis PA, Ruilope LM: Insulin resistance, hyperinsulinemia and renal injury: mechanisms and implications. Am J Nephrol 2006; 26:232-244.

$\checkmark 9$ Srivastava T: Nondiabetic consequences of obesity on kidney. Pediatr Nephrol 2006;21: 463-470.

-10 Kambham N, Markowitz GS, Valeri AM, Lin J, D’Agati VD: Obesity-related glomerulopathy: an emerging epidemic. Kidney Int 2001; 59:1498-1509.
11 Weisinger JR, Kempson RL, Elridge L, Swenson RS: The nephrotic syndrome: a complication of massive obesity. Ann Intern Med 1974;81:440-447.

12 Cohen AH: Massive obesity and the kidney A morphologic and statistical study. Am J Pathol 1975;81:117-130.

-13 Pinto-Sietsma SJ, Navis G, Janssen WMT, de Zeeuw D, Gans ROB, de Jong PE, for the PREVEND Study Group: A central body fat distribution is related to renal function impairment, even in lean subjects. Am J Kidney Dis 2003;41:733-741.

14 Weiss R, Kaufman FR: Metabolic complications of childhood obesity: identifying and mitigating the risk. Diabetes Care 2008;31: 310-316

15 DeFronzo RA, Cooke CR, Andres R, Faloona GR, Davis PJ: The effect of insulin on renal handling of sodium, potassium, calcium, and phosphate in man. J Clin Invest 1975;55: 845-855.

16 Sartori C, Scherrer U: Insulin, nitric oxide and the sympathetic nervous system: at the crossroads of metabolic and cardiovascular regulation. J Hypertens 1999;17:1517-1525.

17 Mogensen CE, Christensen NJ, Gundersen HJ: The acute effect of insulin on heart rate, blood pressure, plasma noradrenaline and urinary albumin excretion: the role of changes in blood glucose. Diabetologia 1980 18:453-457.

18 Chagnac A, Weinstein T, Korzets A, Ramadan E, Hirsch J, Gafter U: Glomerular hemo dynamics in severe obesity. Am J Physiol Renal Physiol 2000;278:817-822.
19 Adelman RD, Restaino IG, Alon US, Blowey DL: Proteinuria and focal segmental glomerulosclerosis in severely obese adolescents. J Pediatr2001;138:481-485.

20 Praga M, Hernandez E, Morales E, Campos AP, Valero MA, Martinez MA, Leon M: Clinical features and long-term outcome of obesity-associated focal segmental glomerulosclerosis. Nephrol Dial Transplant 2001;16: 1790-1798.

21 Verhave JC, Hillege HL, Burgerhof JGM, Navis GJ, de Zeeuw D, de Jong PE, for the PREVEND study group: Impact of sodium intake on urinary albumin excretion is enhanced by obesity. J Am Soc Nephrol 2002;13:661-662.

22 Bello AK, de Zeeuw D, Nahas ME, Brantsma AH, Bakker SJL, de Jong PE, Gansevoort RT: Impact of weight change on albuminuria in the general population. Nephrol Dial Transplant 2007;22:1619-1627.

23 El-Atat FA, Stas SN, McFarlane SI, Sowers JR: The relationship between hyperinsulinemia, hypertension and progressive renal disease. J Am Soc Nephrol 2004;15:2816-2827.

$>24$ Kreisberg JI: Insulin requirement for contraction of cultured rat glomerular mesangial cells in response to angiotensin. II: possible role for insulin in modulating glomerular hemodynamics. Proc Nat Acad Sci USA 1982;79:4190-4192.

25 Ruster C, Wolf G: Renin-angiotensin-aldosterone system and progression of renal disease. J Am Soc Nephrol 2006;17:2985-2991.

$>26$ Abrass CK, Spicer D, Raugi GJ: Insulin induces a change in extracellular matrix glycoproteins synthesized by rat mesangial cells in culture. Kidney Int 1994;46:613-620. 
-27 Murphy LJ, Ghahary A, Chakrabarti S: Insulin regulation of IGF-I expression in rat aorta. Diabetes 1990;39:657-662.

28 Morrisey K, Evans RA, Wakefield L, Phillips AO: Translational regulation of renal proximal tubular epithelial cell transforming growth factor-betal generation by insulin. Am J Pathol 2001;159:1905-1915.

-29 Lupia E, Elliot SJ, Lenz O, Zheng F, Hattori M, Striker GE, Striker LJ: IGF-1 decreases collagen degradation in diabetic NOD mesangial cells: implications for diabetic nephropathy. Diabetes 1999;48:1638-1644.

- 30 Wang S, Denichilo M, Brubaker C, Hirschberg R: Connective tissue growth factor in tubulointerstitial injury of diabetic nephropathy. Kidney Int 2001;60:96-105.

- 31 Schelling JR, Sedor JR: The metabolic syndrome as a risk factor for chronic kidney disease: more than a fat chance? J Am Soc Nephrol 2004;15:2773-2774.

- 32 Sowers JR: Metabolic risk factors and renal disease. Kidney Int 2007;71:719-720.

- 33 Facchini FS, Humphreys MH, DoNascimento CA, Abbasi F, Reaven GM: Relation between insulin resistance and plasma concentrations of lipid hydroperoxides, carotenoids, and tocopherols. Am J Clin Nutr 2000;72: 776-779.

34 Oberg BP, McMenamin E, Lucas FL, McMonagle E, Morrow J, Ikizler TA, Himmelfarb J: Increased prevalence of oxidant stress and inflammation in patients with moderate to severe chronic kidney disease. Kidney Int 2004;65:1009-1016.

- 35 Petrie JR, Ueda S, Webb DJ, Elliott HL, Connell JM: Endothelial nitric oxide production and insulin sensitivity: a physiological link with implications for pathogenesis of cardiovascular disease. Circulation 1996;93:13311333.

36 Williams IL, Wheatcroft SB, Shah AM, Kearney MT: Obesity, atherosclerosis and the vascular endothelium: mechanisms of reduced nitric oxide bioavailability in obese humans. Int J Obes Relat Metab Disord 2002; 26:754-764.

-37 Gruber HJ, Mayer C, Mangge H, Fauler G, Grandits N, Wilders-Truschnig M: Obesity reduces the bioavailability of nitric oxide in juveniles. Int J Obes (Lond) 2008;32:826831.

- 38 Scherrer U, Sartori C: Defective nitric oxide synthesis: a link between metabolic insulin resistance, sympathetic overactivity and cardiovascular morbidity. Eur J Endocrinol 2000;142:315-323.

- 39 Wong CS, Gipson DS, Gillen DL, Emerson S, Koepsell T, Sherrard DJ, Watkins SL, Stehman-Breen C: Anthropometric measures and risk of death in children with end stage renal disease. Am J Kidney Dis 2000;36:811819.

40 Mitsnefes M, Khoury P, McEnery PT: Body mass index and allograft function in pediatric renal transplantation. Pediatr Nephrol 2002;7:535-539.
41 Cofan F, Vela E, Cleries M: Obesity in renal transplantation: analysis of 2691 patients. Transplant Proc 2005;37:3695-3697.

42 Bonnet F, Deprele C, Sassolas A, Moulin P, Alamartine E, Berthezene F, Berthoux F: Excessive body weight as a new independent risk factor for clinical and pathological progression in primary IgA nephritis. Am J Kidney Dis 2001;37:720-727.

43 Filler G, Reimao SM, Kathiravelu A, Grimmer J, Feber J, Drukker A: Pediatric nephrology patients are overweight: 20 years' experience in a single Canadian tertiary pediatric nephrology clinic. Int Urol Nephrol 2007;93: 1235-1240.

44 Cindik N, Baskin E, Agras PI, Kinik ST, Turan M, Saatci U: Effect of obesity on inflammatory markers and renal functions. Acta Pediatr 2005;94:1732-1737.

45 Csernus K, Lanyi E, Erhardt E, Molnar D: Effect of childhood obesity and obesity-related cardiovascular risk factors on glomerular and tubular protein excretion. Eur J Pediatr 2005; 164:44-49.

46 Burgert TS, Dziura J, Yeckel C, Taksali SE, Weiss R, Tamborlane W, Caprio S: Microalbuminuria in pediatric obesity: prevalence and relation to other cardiovascular risk factors. Int J Obes (Lond) 2006;30:273-280.

47 Fowler SM, Kon V, Ma L, Richards WO, Fogo $A B$, Hunley TE: Obesity-related focal and segmental glomerulosclerosis: normalization of proteinuria in an adolescent after bariatric surgery. Pediatr Nephrol 2009;24:851855.

48 Pantoja-Zuzuarregui JR, Mallios R, Murphy J: The effect of obesity on kidney length in a healthy pediatric population. Pediatr Nephrol 2009;24:2023-2027.

- 49 de Jong PE, Verhave JC, Pinto-Sietsma SJ Hillege HL for the PREVEND study group: Obesity and target organ damage: the kidney. Int J Obes (Lond) 2002;26:S21-S24.

50 Valavi E, Alemzadeh Ansari MJ, Ahmadzadeh A: Bardet-Biedl syndrome in a child with chronic kidney disease. Saudi J Kidney Dis Transplant 2009:20:454-457.

51 Abitbol CL, Chandar J, Rodriguez MM, Berho M, Seeherunvong W, Freundlich M, Zillerulo G: Obesity and preterm birth: additive risks in the progression of kidney disease in children. Pediatr Nephrol 2009;24:13631370

52 Caprio S, Plewe G, Diamond MP, Simonson DC, Boulware SD, Sherwin RS, Tamborlane $\mathrm{WV}$ : Increased insulin secretion in puberty: a compensatory response to reductions in insulin sensitivity. J Pediatr 1989;114:963-967.

53 Muntner P, He J, Cutler JA, Wildman RP, Whelton PK: Trends in blood pressure among children and adolescents. JAMA 2004;291:2107-2113.

-54 Sorof JM, Lai D, Turner J, Poffenbarger T, Portman RJ: Overweight, ethnicity, and the prevalence of hypertension in school-aged children. Pediatrics 2004;113:475-482.
55 Lee WWR: An overview of pediatric obesity. Pediatr Diabetes 2007;8:76-87.

56 Sorof J, Daniels S: Obesity hypertension in children: a problem of epidemic proportions. Hypertension 2002;40:441-447.

57 Rosner B, Prineas R, Daniels SR, Loggie J: Blood pressure differences between blacks and whites in relation to body size among US children and adolescents. Am J Epidemiol 2000;151:1007-1019.

58 Nawrot TS, Hoppenbrouwers K, Den Hond E, Fagard RH, Staessen JA: Prevalence of hypertension, hypercholesterolemia, smoking and overweight in older Belgian adolescents. Eur J Public Health 2004;14:361-365.

59 Garrison RJ, Kannel WB, Stokes J 3rd, Castelli WP: Incidence and precursors of hypertension in young adults: the Framingham Offspring Study. Prev Med 1987;16:235-251.

60 Lurbe E, Alvarez V, Liao Y, Tacons J, Cooper R, Cremades B, Torro I, Redon J: The impact of obesity and body fat distribution on ambulatory blood pressure in children and adolescents. Am J Hypertens 1998;11:418-424.

61 Falkner B, DeLoach S: Refining the blood pressure phenotype in children: when does target organ damage begin? Hypertension 2009;53:905-906.

-62 Haysom L, Williams R, Hodson E, LopezVargas P, Roy LP, Lyle D, Craig JC: Risk of $\mathrm{CKD}$ in Australian indigenous and nonindigenous children: a population-based cohort study. Am J Kidney Dis 2009;53:229237.

63 Salvadori M, Sontrop JM, Garg AX, Truong J, Suri RS, Mahmud FH, Macnab JJ, Clark WF: Elevated blood pressure in relation to overweight and obesity among children in a rural Canadian community. Pediatrics 2008; 122:821-827.

64 Marcovecchio ML, Patricelli L, Zito M, Capanna R, Ciampani M, Chiarelli F, Mohn A: Ambulatory blood pressure monitoring in obese children: role of insulin resistance. J Hypertens 2006;24:2431-2436.

65 Cruz ML, Huang TT, Johnson MS, Gower BA, Goran MI: Insulin sensitivity and blood pressure in black and white children. Hypertension 2002;40:18-22.

66 Lurbe E, Torro I, Aguilar F, Alvarez J, Alcon J, Pascual JM, Redon J: Added impact of obesity and insulin resistance in nocturnal blood pressure elevation in children and adolescents. Hypertension 2008;51:635-641.

67 Thearle MS, Bunt JC, Knowler WC, Krakoff J: Childhood predictors of adult acute insulin response and insulin action. Diabetes Care 2009;32:938-943.

68 Bakris GL, Ritz E: The message for World Kidney Day 2009: hypertension and kidney disease - a marriage that should be prevented. Pediatr Nephrol 2009;24:427-430.

69 Lubrano R, Travasso E, Raggi C, Guido G, Masciangelo R, Elli: Blood pressure load, proteinuria and renal function in pre-hypertensive children. Pediatr Nephrol 2009;24: 823-831. 
70 Verhulst SL, Van Hoeck K, Schrauwen N, Haentjens D, Rooman R, Van Gaal L, De Backer W, Desager KN: Sleep-disordered breathing and proteinuria in overweight and obese children and adolescents. Horm Res 2008;70:224-229.

71 Ferris M, Hogan SL, Chin H, Shoham DA, Gipson DS, Gibson K, Yilmaz S, Falk RJ, Jen nette JC: Obesity, albuminuria, and urinalysis findings in US young adults from the Add Health Wave III Study. Clin J Am Soc Nephrol 2007;2:1207-1214.

-72 Nguyen S, McCulloch C, Brakeman P, Portale A, Hsu C: Being overweight modifies the association between cardiovascular risk factors and microalbuminuria in adolescents. Pediatrics 2008;121:37-45.

73 Bangstad HJ, Dahl-Jorgensen K, Kjaersgaard P, Mevold K, Hanssen KF: Urinary albumin excretion rate and puberty in non-diabetic children and adolescents. Acta Paediatr 1993;82:857-862.

74 Mueller PW, Caudill SP: Urinary albumin excretion in children: factors related to elevated excretion in the United States population. Ren Fail 1999;21:293-302.
75 Friedland O, Nemet D, Gorodnitsky N, Wolach B, Eliakim A: Obesity and lipid profiles in children and adolescents. J Pediatr Endocrinol Metab 2002;15:1011-1016.

76 Lane PH: Pediatric aspects of diabetic kidney disease. Adv Chronic Kidney Dis 2005;12: 230-235.

77 Hannon TS, Rao G, Arslanian SA: Childhood obesity and type 2 diabetes mellitus. Pediatrics 2005;116:473-480.

78 Alberti G, Zimmet P, Shaw J, Bloomgarden Z, Kaufman F, Silink M: Type 2 diabetes in the young: the evolving epidemic: the International Diabetes Federation Consensus Workshop. Diabetes Care 2004;27:17981811.

79 Pinhas-Hamiel O, Dolan LM, Daniels SR, Standiford D, Khoury PR, Zeitler P: Increased incidence of non-insulin-dependent diabetes mellitus among adolescents. J Pediatr 1996;128:608-615.

80 Edelstein SL, Knowler WC, Bain RP, Andres R, Barrett-Connor EL, Dowse GK, Haffner SM, Pettitt DJ, Sorkin JD, Muller DC, Collins VR, Hamman RF: Predictors of progression from impaired glucose tolerance to NIDDM an analysis of six prospective studies. Diabetes 1997;46:701-710.
81 Sellers EA, Blydt-Hansen TD, Dean HJ, Gibson IW, Birk PE, Ogborn M: Macroalbuminuria and renal pathology in First Nation youth with type 2 diabetes. Diabetes Care 2009;32:786-790.

82 Pinhas Hamiel O, Lerner-Geva L, Copperman NM, Jacobson MS: Lipid and insulin levels in obese children: changes with age and puberty. Obesity 2007;15:2825-2831.

83 Glowinska B, Urban M, Koput A, Galar M: New atherosclerosis risk factors in obese, hypertensive and diabetic children and adolescents. Atherosclerosis 2003;167:275-286.

84 Nicklas TA, Von Duvillard SP, Berenson GS: Tracking of serum lipids and lipoproteins from childhood to dyslipidemia in adults: the Bogalusa Heart Study. Int J Sports Med 2002;23:S39-S43.

85 Webber LS, Harsha DW, Phillips GT, Srinivasan SR, Simpson JW, Berenson GS: Cardiovascular risk factors in Hispanic, white, and black children: the Brooks County and Bogalusa Heart studies. Am J Epidemiol 1991;133:704-714. 